\title{
Determination of the Hot Cracking Tendency of a Twin-Roll Cast AZ31 Magnesium Alloy by Means of Gleeble Tests
}

\author{
Heike Wemme ${ }^{1, a^{*}}$, Christina Krbetschek ${ }^{2, b}$, Madlen Ullmann ${ }^{1, c}$, \\ Anna Freigang ${ }^{1, d}$, Stefan Plach ${ }^{1, d}$ and Rudolf Kawalla ${ }^{1, d}$ \\ ${ }^{1}$ Technische Universität Bergakademie Freiberg, Institute of Metal Forming, \\ Bernhard-von-Cotta-Str. 4, 09599 Freiberg, Germany \\ ${ }^{2}$ Technische Universität Bergakademie Freiberg, Institute of Materials Science, \\ Gustav-Zeuner-Str. 5, 09599 Freiberg, Germany \\ aHeike.Wemme@imf.tu-freiberg.de, ${ }^{\mathrm{b}}$ Christina.Krbetschek@iww.tu-freiberg.de, \\ 'Madlen.Ullmann@imf.tu-freiberg.de, doffice@imf.tu-freiberg.de
}

Keywords: magnesium alloy, AZ31, hot cracking, HTBR, twin-roll casting

\begin{abstract}
The knowledge of the formation of hot cracks in magnesium alloys is fundamental for good quality in the production and further processing of the strips. Whether an alloy is susceptible to hot cracking and into which temperature range, can be taken into account during production and further processing. As a result, production rejects due to hot cracking can be minimized. Affected production steps can be casting, continuous casting, twin-roll casting, rolling or welding.

Hot cracking often occurs in the so-called mushy zone, when solid phases and melt coexist, at temperatures where the material no longer exhibits ductility. For the evaluation of the hot cracking tendency of an alloy, the width of the HTBR (high-temperature brittleness range) can be used.

On the basis of a test on a Gleeble HDS-V40, the HTBR was determined for a twin-roll cast AZ31 magnesium alloy. The transition between ductile forming behaviour and complete brittle reaction of the AZ31 alloy is confirmed by the observation of the fracture surfaces (determination of the fracture type) in the scanning electron microscope (SEM) and can be found at $555^{\circ} \mathrm{C}$. The HTBR shows a range $35 \mathrm{~K}$.
\end{abstract}

\section{Introduction}

Of all construction metals, magnesium has the lowest density with a high specific strength and is thus a promising material to reduce the weight of components. This is an important approach to reduce fuel consumption in automobiles and reduce $\mathrm{CO}_{2}$ emissions. [1] In recent years, double-digit growth rates have been recorded by the application of magnesium components, mainly castings. Magnesium also has a high potential in the aerospace and electrical industry. [2]

In general, wrought magnesium alloys contain aluminium, zinc and manganese as major alloying elements. A typical alloy series is the AZ series, in which, for example, the alloy AZ31 is represented. [3] A weak point of these alloys, depending on the production process, could be hot cracks. The hot cracking susceptibility of an alloy can be described by the width of their HTBR shown in Fig. 1. The HTBR is the range between the NST (nil-strength temperature) and the DRT (ductility recovery temperature). The NST is the temperature at which the material is liquefied to such an extent that there are no solid bonds between the individual grains and no forces can be absorbed. The DRT describes the temperature at which there are sufficiently firm connections between the grains during cooling of the alloy, so that the material can exhibit plastic deformation. The HTBR is the range in which hot cracking can occur. The larger this range, the higher the probability of the formation of hot cracks $[4,5]$.

According to Adamiec, the value of the HTBR depends on the amount of the low-melting intermetallic $\gamma$-phase $\mathrm{Mg}_{17}(\mathrm{Al}, \mathrm{Zn})_{12}$, which is formed during solidification of $\mathrm{AZ}$ alloys [6]. The melting temperature of the pure $\mathrm{Mg}_{17} \mathrm{Al}_{12}$ phase is $436{ }^{\circ} \mathrm{C}$ [7]. Just below this point, the dissolution of the $\gamma$-phase is very low, but above this, it increases strongly [8]. The melting during heating or the late solidification during cooling of the remaining melt leads to a reduction in the formability. If 
an extremely small tensile force is applied to the material, a separation of the magnesium solid solution crystal dendrites $(\alpha-\mathrm{Mg})$ occurs. $[9,10]$

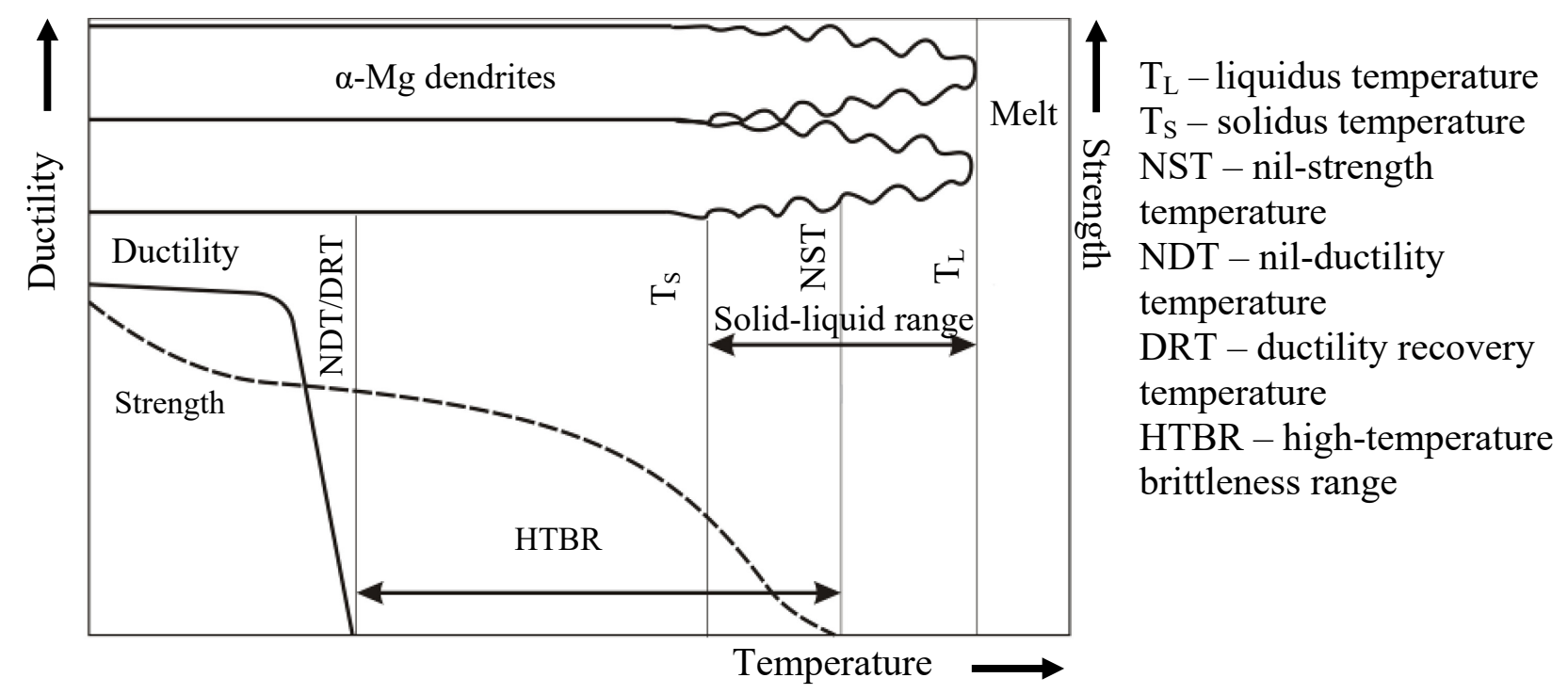

Fig. 1. Range of high-temperature brittleness (HTBR) based on [6]

The HTBR also depends on the initial state of the structure of the alloy, such as whether a casting structure has been subjected to heat treatment [6]. Other influencing factors are technological parameters for example the amount of heat input and the cooling rate [4].

Another criterion for assessing the hot cracking susceptibility of an alloy is the temperature range between NST and NDT. The NDT (nil-ductility temperature) corresponds to the temperature at which the alloy can no longer receive plastic deformation when heated. According to [11], the probability of the formation of hot cracks is strongly reduced if this range is less than $20 \mathrm{~K}$. This temperature range and the HTBR are to be determined for twin-roll cast AZ31 magnesium alloy in this paper.

\section{Experimental Procedure}

The chemical composition of the tested AZ31 magnesium alloy is shown in Table 1. The melting temperature of this alloy composition is $629^{\circ} \mathrm{C}$ [12]. Sheets with a thickness of $5.3 \mathrm{~mm}$ were produced via twin-roll casting (TRC).

Table 1. Chemical composition of the alloy AZ31 in weight percentage

\begin{tabular}{|l|l|l|l|l|l|l|l|}
\hline $\mathrm{Al}$ & $\mathrm{Zn}$ & $\mathrm{Mn}$ & $\mathrm{Si}$ & $\mathrm{Ni}$ & $\mathrm{Sn}$ & $\mathrm{Pb}$ & $\mathrm{Mg}$ \\
\hline 2.77 & 1.07 & 0.37 & 0.01 & 0.01 & 0.01 & 0.01 & 95.75 \\
\hline
\end{tabular}

The HTBR depends on the initial state of the alloy [6]. The microstructure of twin-roll cast strips and the chemical composition is not homogeneous over the strip thickness due to the combination of solidification and rolling processes in the TRC mill [2]. Therefore, flat twin roll cast tensile specimens with an adapted geometry were used for the hot cracking tests on the Gleeble HDS-V40 (see Fig. 2; sample thickness corresponds to strip thickness). 


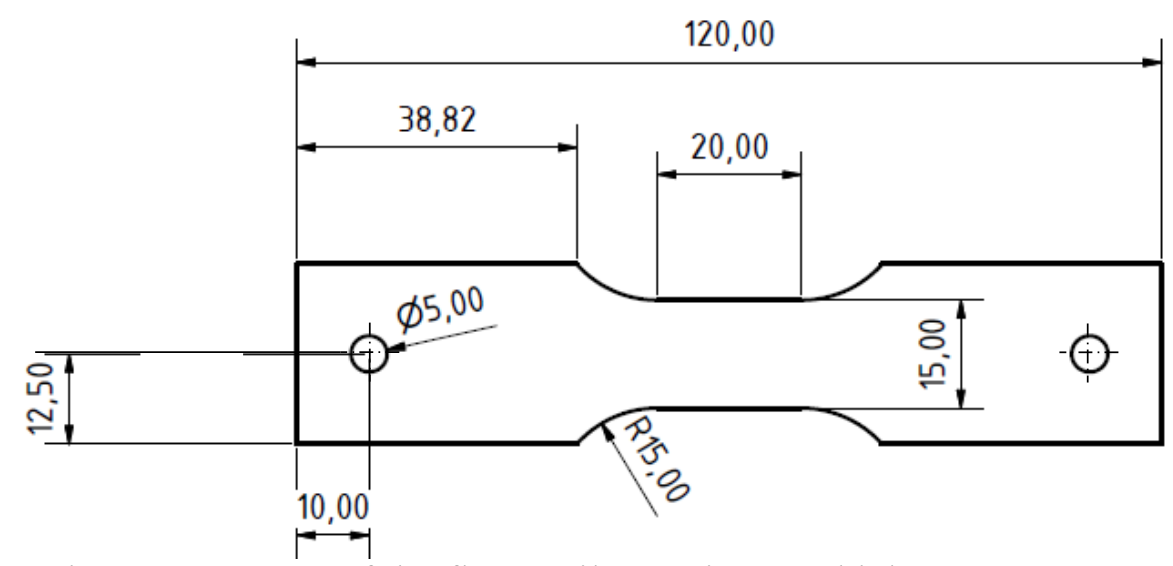

Fig. 2. Geometry of the flat tensile specimens, thickness $5.3 \mathrm{~mm}$

For the determination of the NST, the tensile specimens were subjected to a low load of $0.2 \mathrm{kN}$ and then heated up to the fracture according to the scheme in Fig. 3 . Up to $500{ }^{\circ} \mathrm{C}$, the heating rate was $5 \mathrm{~K} / \mathrm{s}$, after $500{ }^{\circ} \mathrm{C}$ it was $1 \mathrm{~K} / \mathrm{s}$ until breakage. The temperature at break agrees to the NST. All specimens were tested under an argon atmosphere and cooled rapidly after the test with argon gas.

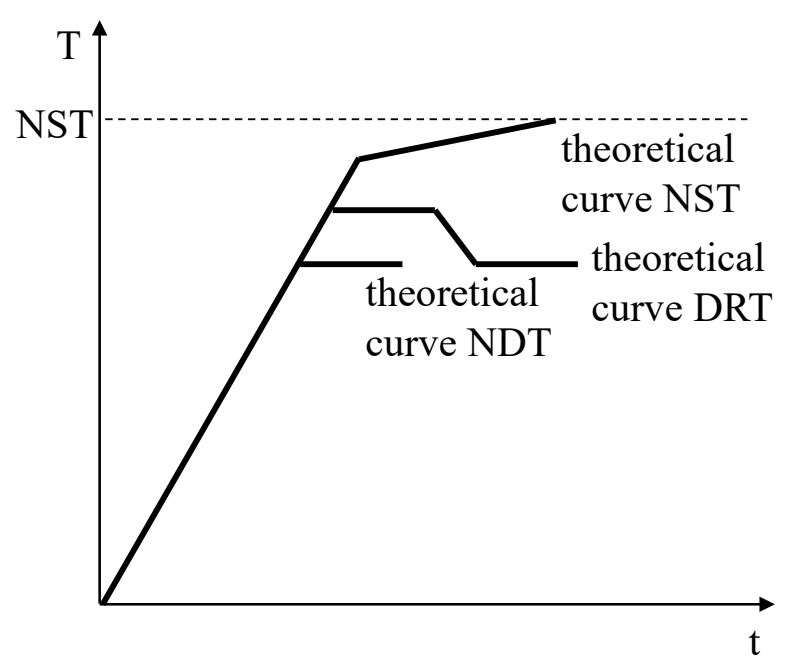

Fig. 3. Theoretical curve from a Gleeble test for determining NST, NDT and DRT

The NDT was determined by heating tensile specimens to various temperatures below the NST (test range between $495{ }^{\circ} \mathrm{C}$ and $575{ }^{\circ} \mathrm{C}$ ), keeping at temperature for $10 \mathrm{~s}$ and deforming until fracture (see Fig. 3). It was determined on the basis of the evaluation of the necking. The necking was measured with a sliding calliper and calculated using the following equation:

$$
Z=\frac{A_{0}-A_{B}}{A_{0}} * 100 \%
$$

where $\mathrm{Z}=$ Reduction of area, $\mathrm{A}_{0}=$ Cross section before deformation, $\mathrm{A}_{\mathrm{B}}=$ Cross section after fracture.

A similar experiment was selected for the DRT. The tensile specimens were heated to $15 \mathrm{~K}$ under NST, cooled down with argon gas to the test temperature and deformed to the break. The temperature, at which a necking due to a plastic deformation can be observed, corresponds to the DRT. In order to assess the nature of the fracture, the fracture surfaces were also examined in a SEM. In addition, light microscope picture of a twin-roll cast strip and of a TRC Gleeble sample after the NST test were taken.

\section{Results and Discussion}

Light microscope pictures of a TRC strip cross-section are shown in Fig. 4 a). The formation of the microstructure depends on various process parameters. Due to the heat dissipation over the rolls, the melt first solidifies at the surface of the strips and finally in the center, similar to the 
solidification of an ingot cast [13]. The structure of the sheets can be divided into three zones: the fine edge zone with globulitic grains that solidifies quickly on the rolls of the mill, the intermediate columnar zone and the globular inner zone in which the melt has solidified last. In the intermediate columnar zone, columnar magnesium solid solution crystals $(\alpha-\mathrm{Mg})$ with a herringbone structure, tilted to rolling direction, are formed, which are partially destroyed through a first rolling pass during TRC. [2] Between the $\alpha-\mathrm{Mg}$ grains and in the middle of the strip (center segregation) is an inhomogeneous microstructure of low-melting phases with high phase fraction of aluminium and zinc. These segregations result from the residual melt during the solidification.
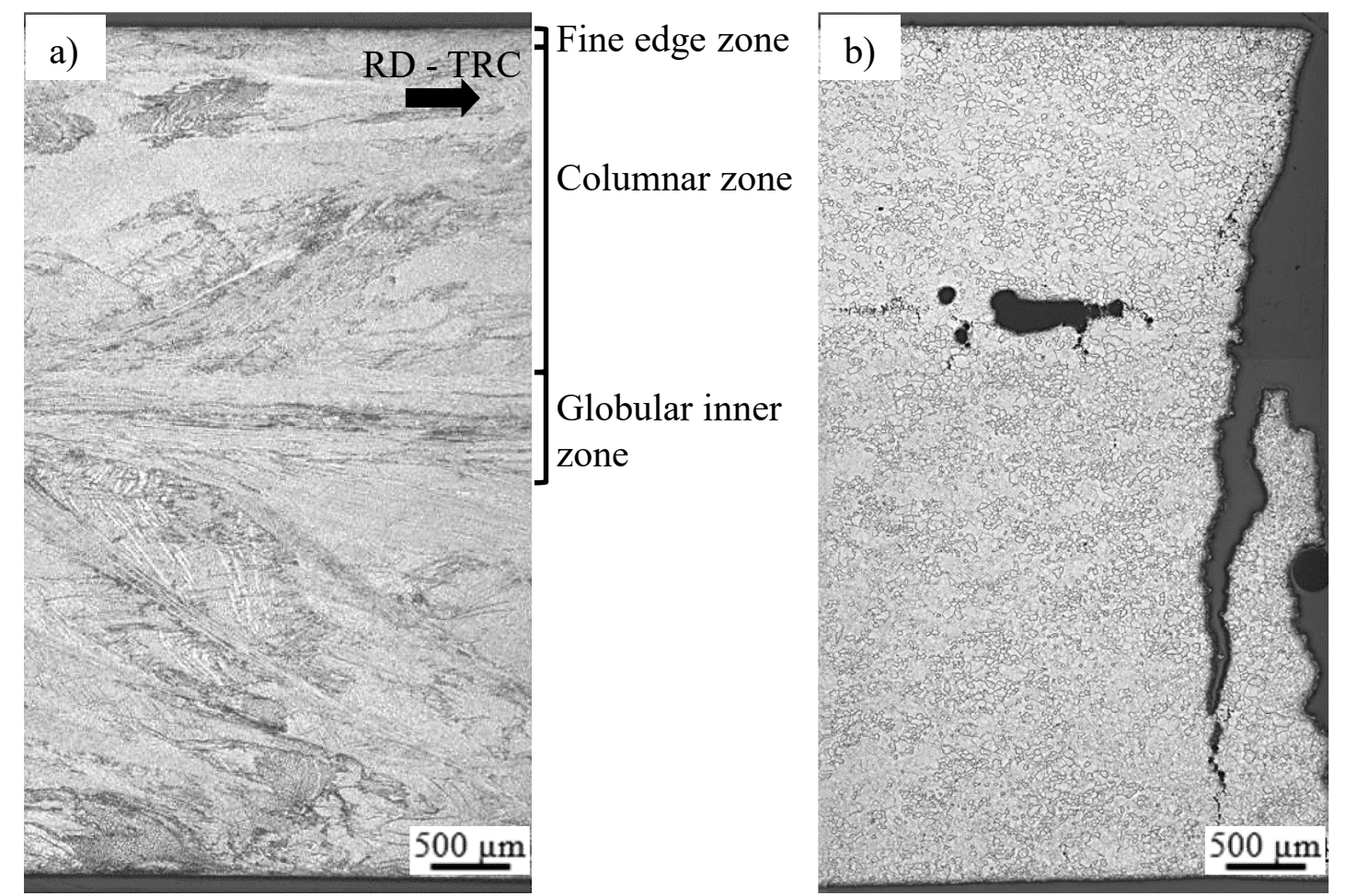

Fig. 4. a) Light microscope picture: cross section of a twin-roll cast sheet (rolling direction marked

(RD)), b) Light microscope picture: cross section of a TRC Gleeble sample after a NST-test

The results of the NST tests indicated a temperature of $590{ }^{\circ} \mathrm{C}$ for the material liquefaction. This result is compared with the NST of AZ casting alloys with different aluminium contents (see Fig. 5) $[6,14]$.

The determined value fits well with the literature values. Compared to a cast AZ31 alloy with an aluminium content of $3.0 \mathrm{wt} . \%$ and an NST of $580{ }^{\circ} \mathrm{C}$, the deviation of $10 \mathrm{~K}$ is well justified with the slightly higher aluminium content and furthermore a faster solidification during the TRC process, with a different microstructure compared with cast alloys. The NST values for the alloys AZ61 and AZ91 confirm the strong influence of the aluminium content. They show a nearly linear dependency. Solidified remaining melt, enriched with the alloying elements aluminium and zinc, initiates hot cracking. An increasing aluminium content lead to a rise of segregation phases with low melting points and therefore to a lesser NST. 


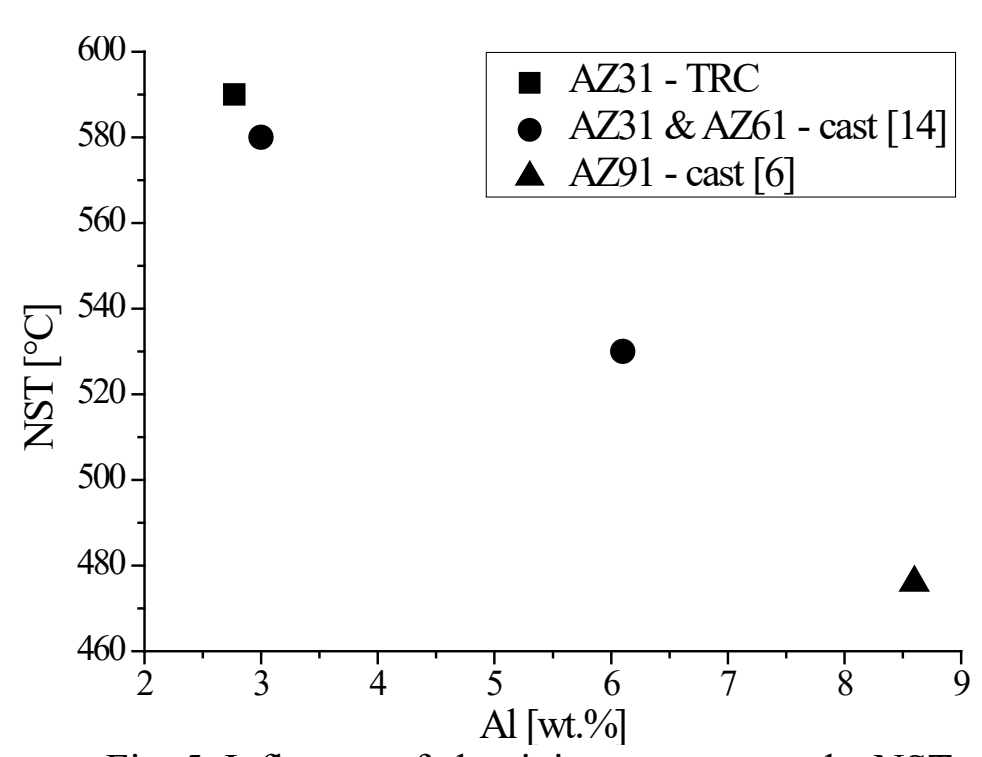

Fig. 5. Influence of aluminium content on the NST

The microstructure of an NST sample in the fracture region was examined using a light microscope (Fig. 4 b)). The columnar structure change into a globulitic microstructure by the heat input. The fracture runs along the grain boundaries (transcrystalline fracture). In the heat-affected zone, the segregation in the center segregation and between the grains partly melted. Here, the composition of the segregation phases was determined by means of energy dispersive X-ray spectroscopy (EDS, see Fig. 6).
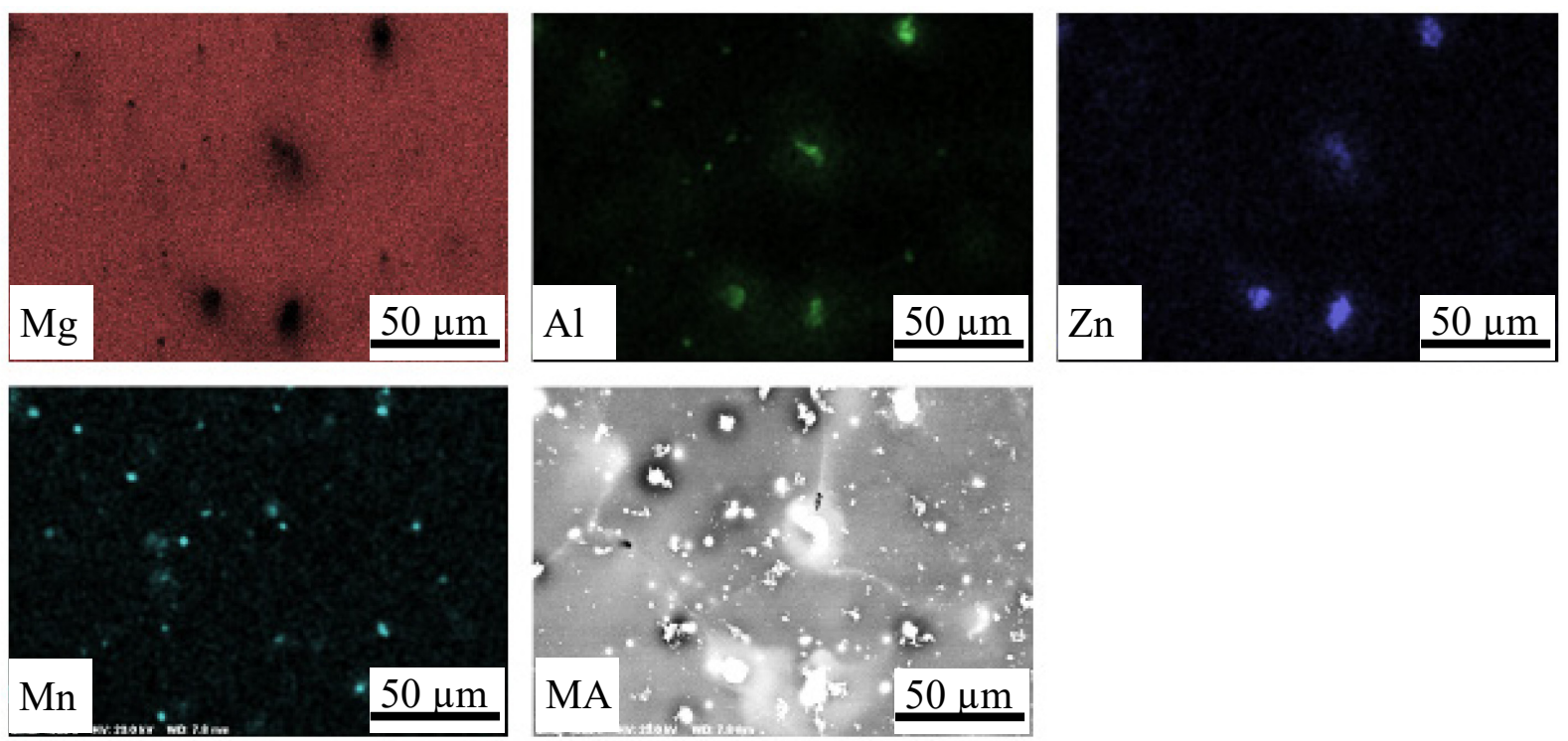

Fig. 6. EDX-Mapping: cross section of a TRC Gleeble sample after a NST-test (MA - measurement area; measured at $2 / 3$ height of the strip height near the breakage)

Increased contents of the alloying elements aluminium and zinc were measured. Due to the size of the measuring spot, which also always measures the surrounding material, the EDS could not determine an accurate composition. However, previous studies using X-Ray diffraction (XRD) revealed that the $\gamma$-phase $\mathrm{Mg}_{17}(\mathrm{Al}, \mathrm{Zn})_{12}$ and under certain conditions the $\varphi$-phase $\mathrm{Al}_{2} \mathrm{Mg}_{5} \mathrm{Zn}_{2}$ plus particles of $\mathrm{Al}_{8} \mathrm{Mn}_{5}$ are present in the segregation of the TRC strip [7, 15].

The HTBR of the twin-roll cast magnesium sheets is the result of the temperature range between the NST and the DRT. From DRT experiments (see Fig. 7 a)) becomes clear that plastic deformation take place at a temperature of $555^{\circ} \mathrm{C}$, while the material shows a brittle fracture behavior above this temperature. 


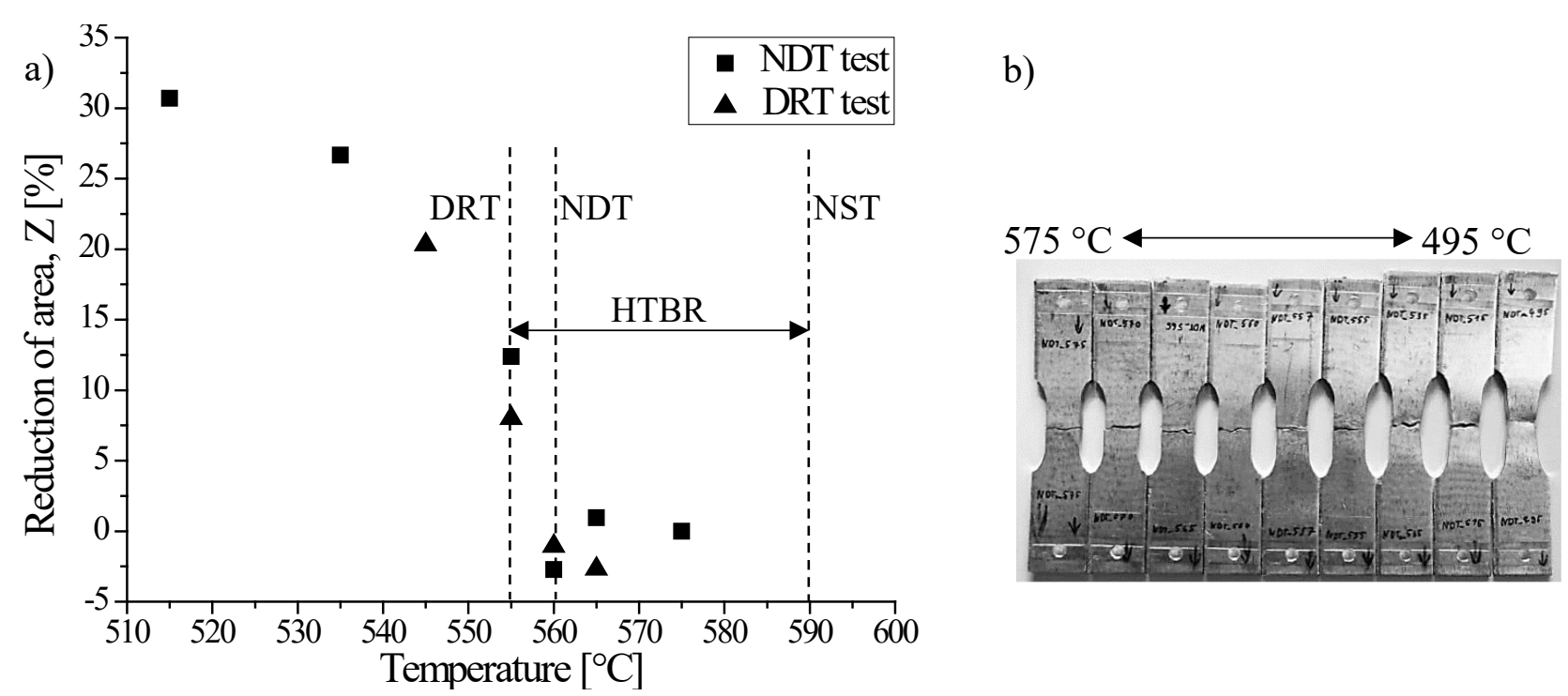

Fig. 7. a) Reduction of the area $\mathrm{Z}$ as a function of temperature,

b) NDT samples from $495^{\circ} \mathrm{C}$ to $575^{\circ} \mathrm{C}$

Thus, for the HTBR with a NST of $590{ }^{\circ} \mathrm{C}$ and a DRT of $555^{\circ} \mathrm{C}$, a temperature range of $35 \mathrm{~K}$ was determined. This temperature range characterises the area where hot cracking can primary occur. In forming processes, it should be considered that the forming does not occur in this temperature range.
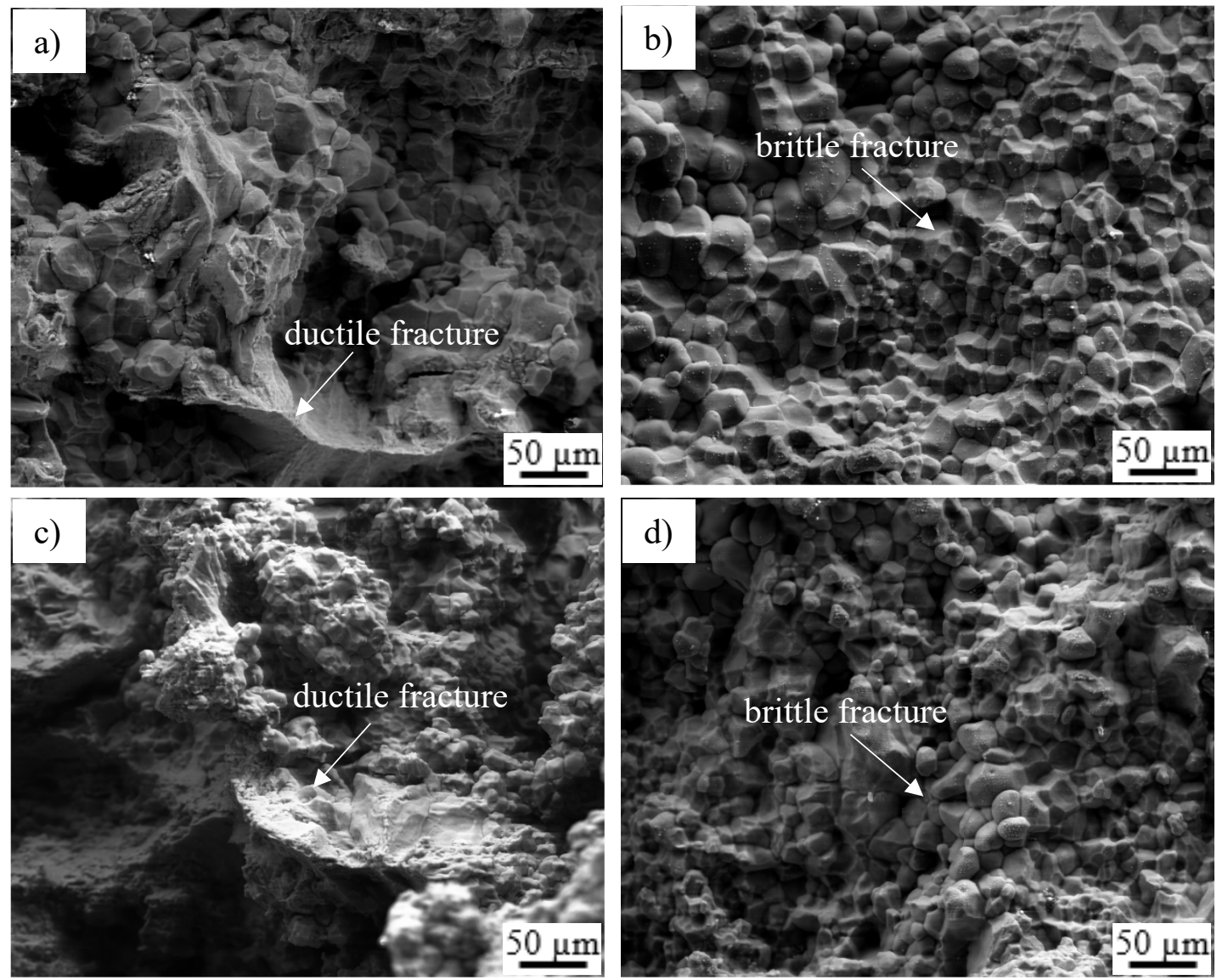

Fig. 8. Fractured surfaces of the DRT samples at a) $545{ }^{\circ} \mathrm{C}$ and b) $565^{\circ} \mathrm{C}$ and of the NDT samples at c) $555^{\circ} \mathrm{C}$ and d) $565^{\circ} \mathrm{C}$

A value of $560{ }^{\circ} \mathrm{C}$ is obtained for the NDT. The different elongation at break and necking of the NDT samples as a function of the temperature can also be seen visually (Fig. $7 \mathrm{~b}$ )). The temperature difference between NST and NDT will take $30 \mathrm{~K}$. Therefore, according to the evaluation criterion of [11], the susceptibility to hot cracking is given since the temperature range is higher than $20 \mathrm{~K}$. 
The minus values in the reduction of area are caused by selective small fusings at the edge of the sample which protrude a little over the cross-section.

The fractured surfaces of the samples $10 \mathrm{~K}$ above and below the DRT are shown in Fig. $8 \mathrm{a}$ ) and b). At a temperature of $545^{\circ} \mathrm{C}$ (Fig 8 a)), a fracture with brittle and ductile fractions can be clearly seen. At a temperature of $565^{\circ} \mathrm{C}$ (Fig. 8 b)), the sample shows a brittle fractured surface. No plastic deformation has occurred in the material. The break runs along the grain boundaries.

The same behaviour could be seen for the samples taken $5 \mathrm{~K}$ above and below the NDT. A fracture with brittle and ductile fractions exists in the sample, which was deformed at a temperature of $555{ }^{\circ} \mathrm{C}$ (Fig. $8 \mathrm{c}$ )). In contrast to this temperature, the $565{ }^{\circ} \mathrm{C}$ sample exhibit a pure intercrystalline brittle fracture (Fig. $8 \mathrm{~d}$ )). These images confirm the DRT and NDT temperatures previously determined by the necking.

\section{Summary}

- The NST, DRT and NDT were determined with the help of Gleeble tests for a twin-roll cast AZ31 alloy. The performed measurements have shown a value of $590{ }^{\circ} \mathrm{C}$ for the NST. In context with a DRT of $555^{\circ} \mathrm{C}$, an HTBR of $35 \mathrm{~K}$ was determined. Hot cracking primary takes place in this temperature range. The experimental determined NDT was $560^{\circ} \mathrm{C}$. Therefore, the difference of temperature between NST and NDT is $30 \mathrm{~K}$. This value is above the limit of $20 \mathrm{~K}$ for a low hot crack probability [11]. It can be expected that hot cracking occur in the AZ31 alloy.

- A consideration of NST's of the different AZ-magnesium alloys (AZ31, AZ61 and AZ91) revealed a strong dependence of the NST on the aluminium content. Using AZ31 TRC samples, the NST shows only a small increase in comparison with the cast material indicating a low influence whether the material is cast or twin-roll cast.

- The fracture surfaces of the DRT and NDT samples confirm the temperatures determined by the necking.

- In the initial state, the tested alloy AZ31 (twin-roll cast) shows a microstructure similar to an ingot cast structure. During the solidification in the TRC process, secondary phases with lower melting points arise between the $\alpha-\mathrm{Mg}$ areas. In the NST tests, these phases melted and the material fails. EDX studies showed that the low-melting phases contain aluminium, magnesium and zinc.

\section{Acknowledgment}

The authors would like to thank the European Regional Fond for financial support through the project No. 100270111.

\section{References}

[1] B.L. Mordike, T. Ebert, Magnesium Properties - applications - potential, Materials Science and Engineering A302 (2001) 37-45.

[2] M. Ullmann, F. Berge, K. Neh, R. Kawalla, Development of a rolling technology for twin-roll cast magnesium strips, Metalurgija 54 (2015) 711-714.

[3] J. Bohlen, D. Letzig, K.U. Kainer, New Perspectives for Wrought Magnesium Alloys, Materials Science Forum 564-549 (2007) 1-10.

[4] J. Adamiec, Weldability of cast magnesium alloy, Silesian University Publication, Gliwice, (2010).

[5] J. Lancaster, Handbook of Structural Welding, first ed., Abington Publishing, Abington, 1997. 
[6] J. Adamiec, Assessment of High-Temperature Brittleness Range of the Casted Alloy AZ91, Materials Science Forum 690 (2011) 41-44.

[7] U. Lukas, in: G. Effenberg (Ed.), MSI, Materials Science International Services GmbH, Stuttgart, 2004

[8] J. Mohammadi, M. Ghoreishi, Y. Behnamian, An Investigation into the Dissolution Characteristics of $\gamma$ Precipitates in Mg-3Al-Zn Alloy, Materials Research 17(4) (2014) 996-1002.

[9] Y. Wang, B. Sun, Q. Wang, Y. Zhu, W. Ding, An understanding of the hot tearing mechanism in AZ91, Materials Letters 53 (2002) 35-39.

[10]C.J. Huang, C.M. Cheng, C.P. Chou, F.H. Chen, Hot Cracking in AZ31 and AZ61 Magnesium Alloy, J. Mater. Sci. Technol. 27(7) (2011) 633-640.

[11]Dynamic Systems Inc. „Gleeble System NST and Low Force Jaws“. In: The Gleeble NEWSLETTER (2006).

[12]H.P. Heller, P.R. Scheller, Bericht: Ermittlung der Liquidus- und Solidustemperatur von Magnesiumlegierungen, Institut für Eisen- und Stahltechnologie, TU Bergakademie Freiberg (2005).

[13]I. Polmear, D. StJohn, J.-F. Nie, M. Qian, Casting of Light Alloys, in: Light Alloys: Metallurgy of the Light Metals, fifth Edition, Butterworth-Heinemann, Oxford, 2017, pp. 112-113.

[14]E. Hadasik, D. Kuc, High-Temperature characteristics of plasticity of Magnesium Alloys, Silesian University Publication, Brno (2014).

[15]C. Krbetschek, F. Berge, M. Oswald, M. Ullmann, R. Kawalla, Microstructure investigations of inverse segregations in twin-roll cast AZ31 strips, Magnesium Technology, TMS (2016) 369-374. 